\title{
Produção de concreto autoadensável incorporado com resíduo da indústria de cerâmica vermelha
}

\author{
Production of self-compacting concrete \\ incorporated with red clay industry waste
}

Rafael Francisco Cardoso dos Santos ${ }^{1}$, Alessandra Lorenzetti de Castro ${ }^{2}$, Karoline Mariana Gonçalves ${ }^{1}$

\author{
${ }^{1}$ Laboratório de Materiais de Construção Civil, Instituto de Pesquisas Tecnológicas do Estado de São Paulo (IPT) - Av. \\ Prof. Almeida Prado, 532, Butantã, São Paulo, SP, Brasil. \\ e-mail: rafaelfc@ipt.br \\ ${ }^{2}$ Departamento de Engenharia de Estruturas, Escola de Engenharia de São Carlos, Universidade de São Paulo - Av. Tra- \\ balhador Sancarlense, 400, Centro, São Carlos, SP, Brasil. \\ e-mail: alcastro@sc.usp.br; kamariana@ipt.br
}

\section{RESUMO}

Nos últimos anos, observa-se uma crescente utilização de adições minerais na produção de cimento Portland e de concretos com o intuito de melhorar as propriedades físicas, mecânicas e de durabilidade desses materiais, além dos benefícios econômicos e ambientais, já que essas adições geralmente são resíduos ou subprodutos industriais. Considerando que a indústria de cerâmica vermelha do Brasil gera uma elevada quantidade de resíduos no processo de produção, existe um passivo ambiental e um custo elevado relacionados a esses resíduos. Uma alternativa de aproveitamento consiste na sua utilização como adição mineral na produção de cimento Portland e concreto. Assim, o presente trabalho avalia a utilização de resíduos de cerâmica vermelha na produção de concreto autoadensável. Além das propriedades de autoadensabilidade no estado fresco, foram determinadas as propriedades físicas e mecânicas no estado endurecido. Os resultados demonstram que o material possui um grande potencial para utilização na produção de concreto autoadensável, inclusive aqueles de alta resistência.

Palavras-chave: resíduo; cerâmica vermelha; adição mineral; cimento composto; concreto autoadensável.

\begin{abstract}
In recent years, there has been an increasing use of mineral additions in the production of Portland cement and concrete in order to improve the physical, mechanical and durability properties of these materials, in addition to economic and environmental benefits as these additions are generally industrial waste or byproducts. Whereas the red clay industry in Brazil generates a high amount of waste from the production process, there is an environmental liability and higher costs related to such waste. An alternative utilization is its incorporation as a mineral addition in the production of Portland cement and concrete. Thus, the present study evaluates the use of red clay industry waste in the production of self-compacting concrete. Besides the selfcompacting properties in fresh state, physical and mechanical properties were evaluated in the hardened state. The results show that the material has a great potential for use in the production of self-compacting concrete, including those of high strength.
\end{abstract}

Keywords: waste; red clay; mineral addition; blended cements; self-compacting concrete.

\section{INTRODUÇÃO}

A construção civil tem papel fundamental para atingir os objetivos globais do desenvolvimento sustentável, uma vez que o setor consome grande quantidade de recursos naturais e gera grande quantidade de resíduos sólidos e gases poluentes, não só na fase de extração das matérias-primas, como também na fabricação, no transporte, no uso, na manutenção e no descarte dos resíduos gerados.

Dentre os materiais empregados na construção civil, o concreto merece destaque por ser o material 
mais consumido no mundo depois da água. Entre seus impactos ambientais, um dos mais importantes é a emissão de $\mathrm{CO}_{2}$, sendo que a grande maioria dessas emissões está relacionada com a produção do cimento Portland constituinte da mistura. O processo de produção do cimento é um dos processos industriais mais poluidores, sendo responsável por cerca de $5 \%$ das emissões mundiais de $\mathrm{CO}_{2}$. Cerca da metade das emissões de $\mathrm{CO}_{2}$ vinculadas ao processo de produção do cimento ocorre durante a descarbonatação do calcário para transformar-se no clínquer (etapa da clinquerização), outra parcela é predominantemente resultante da queima de combustíveis fósseis no forno de clínquer, além das emissões ligadas ao transporte de matérias-primas e ao uso da eletricidade [1].

Três vetores concentram as iniciativas da indústria cimenteira brasileira e mundial para a mitigação dos gases de efeito estufa: a eficiência energética, o uso de combustíveis alternativos ou de fontes renováveis, e o uso de cimento composto com adições [1]. No caso do uso de cimentos compostos, a mitigação das emissões dos gases de efeito estufa está relacionada com a redução do teor de clínquer no cimento por meio da incorporação de adições minerais, como escórias, materiais pozolânicos e fíler calcário. No caso dos concretos, é possível substituir parcialmente o cimento Portland por um ou uma combinação de dois ou três materiais cimentícios suplementares, o que pode ser vantajoso não apenas do ponto de vista econômico, mas também do ponto de vista reológico, de resistência mecânica e de durabilidade [2].

\subsection{Adições minerais}

A incorporação de adições minerais na produção de cimentos e concretos tem aumentado nos últimos anos, e fatores ambientais, econômicos e tecnológicos têm um papel importante nesse crescimento. As adições minerais fornecem conforto ambiental, pois resíduos e subprodutos industriais são reciclados, emissões perigosas lançadas na atmosfera são reduzidas, matérias-primas são preservadas e energia é economizada [3]. Com controle de qualidade adequado, grandes quantidades de diversos resíduos e subprodutos industriais podem ser incorporadas ao concreto, seja na forma de cimento Portland composto ou de adição mineral: normalmente, a incorporação de adições minerais ao cimento e ao concreto é feita em quantidades que variam entre $20 \%$ e 70\% por massa de material cimentício [4].

Do ponto de vista tecnológico, por interagir química e fisicamente com os produtos da hidratação do clínquer ou do cimento, as adições minerais modificam a microestrutura do material e, com isso, melhoram propriedades de materiais à base de cimento, como as argamassas e os concretos [4]. O efeito químico está associado à reação pozolânica, ou seja, a reação da adição mineral com o hidróxido de cálcio formado durante a hidratação do cimento, formando silicato de cálcio hidratado adicional. Fisicamente os efeitos gerados consistem no efeito microfiler, resultante do aumento da densidade da mistura pelo preenchimento de espaços vazios pelas partículas das adições; refinamento de poros, causado pelas pequenas partículas das adições que podem agir como pontos de nucleação para produtos de hidratação; e alteração da microestrutura da zona de transição entre a pasta de cimento e o agregado, reduzindo ou eliminando o acúmulo de água livre que fica retido sob os agregados, bem como preenchendo os espaços vazios deixados pelas partículas de cimento próximas à superfície do agregado e reduzindo a concentração de hidróxido de cálcio na região devido à reação pozolânica [5].

Neste contexto situa-se a incorporação da pozolana obtida a partir de resíduos da indústria de cerâmica vermelha que, combinada em proporções adequadas com o cimento Portland de alta resistência inicial disponível no mercado, resulta na produção de cimento composto com pozolana (CPII Z) e cimento pozolânico (CPIV). Além disso, a pozolana obtida pode ser utilizada como adição mineral na produção de concretos aplicados na construção civil, incorporada em substituição ao cimento, a fim de conferir propriedades específicas para esses materiais, especialmente em termos de resistência mecânica e durabilidade.

A aplicação de resíduos de cerâmica vermelha como adição mineral para a produção de cimento Portland e concreto foi considerada em função da sua composição química ser compatível com a composição química de outros materiais utilizados para a mesma finalidade [6-12]. A indústria de cerâmica vermelha utiliza a chamada massa monocomponente, composta basicamente por argilas. No entanto, como os minerais da argila apresentam uma estrutura cristalina, a argila em forma bruta não possui propriedades pozolânicas, sendo necessário aplicar um tratamento térmico para torná-la reativa. $\mathrm{O}$ tratamento térmico altera a estrutura cristalina das argilas por meio de transformações químicas, formando um aluminossilicato com estrutura amorfa, que determina o grau de atividade pozolânica do material $[7 ; 8 ; 9]$. Quando devidamente cominuídas, a reatividade desses materiais apresenta basicamente caráter pozolânico. No Brasil, como as temperaturas de queima empregadas no processo de produção dos blocos e telhas cerâmicas usualmente variam entre $700^{\circ} \mathrm{Ce}$ $900^{\circ} \mathrm{C}$, os resíduos desses componentes da construção, moídos em finura adequada, podem se tornar pozolanas ativas se a argila de origem (composição mineralógica, química e física) e o processo de queima (tempe- 
ratura) fornecerem as condições necessárias para isso.

\subsection{Concreto autoadensável}

O concreto autoadensável foi desenvolvido na Universidade de Tóquio, no Japão, na década de 1980, devido à necessidade de se obter estruturas mais duráveis, com economia e menor tempo de execução, tendo em vista a proporção otimizada dos componentes da mistura e a ausência da necessidade do adensamento mecânico do concreto [13]. Esse concreto está relacionado com o aumento na produtividade, redução de mão-deobra e melhora da qualidade e da segurança do ambiente de trabalho, contribuindo com a tecnologia sustentável do concreto. É caracterizado como um material ambientalmente correto, uma vez que utiliza grandes quantidades de resíduos industriais em sua composição. Por essas e outras razões, o concreto autoadensável é cada vez mais empregado como material de construção, tanto nos setores de pré-moldados e pré-fabricados, quanto para aplicações em elementos de concreto moldados no local [14].

Para um concreto ser considerado autoadensável, este deve apresentar simultaneamente três propriedades no estado fresco $[13 ; 15 ; 16]$ :

- habilidade de preenchimento (fluidez): definida como a capacidade do concreto escoar dentro da fôrma preenchendo todos os espaços, somente pela ação do seu peso próprio. Os mecanismos que governam essa propriedade são a alta fluidez e a coesão da mistura;

- habilidade passante: definida como a capacidade de escoamento pela fôrma, passando por entre os obstáculos (armadura e seções reduzidas) sem sofrer bloqueio do fluxo, isto é, deve apresentar coesão necessária para que a mistura escoe intacta entre as barras de aço da armadura. Os mecanismos que governam esta propriedade são a viscosidade da pasta e da argamassa e as características dos agregados, e;

- $\quad$ resistência à segregação: caracteriza a capacidade do concreto em se manter coeso quando escoar dentro das fôrmas, passando ou não através de obstáculos, sem que haja a ocorrência de segregação e/ou exsudação de seus componentes. Esta propriedade melhora a uniformidade da mistura durante o transporte, lançamento e consolidação do material, sendo governada pela viscosidade e coesão da mistura.

Assim, o concreto autoadensável pode ser definido como o concreto capaz de escoar no interior das fôrmas, passando pela armadura de reforço e preenchendo-a naturalmente, sob influência apenas do seu peso próprio. A capacidade de autoadensabilidade é obtida com o equilíbrio entre a alta fluidez e a moderada viscosidade do material. A alta fluidez é alcançada com a utilização de aditivos superplastificantes, enquanto a moderada viscosidade e a coesão são conseguidas com o incremento de um percentual adequado de materiais com granulometria muito fina (adição mineral, fíler) e/ou aditivos modificadores de viscosidade.

Na prática, os materiais utilizados na dosagem de um concreto autoadensável são os mesmos de um concreto convencional, porém com algumas mudanças nas características de alguns componentes, acrescido de aditivos químicos e de materiais finos. Em relação ao concreto convencional, adensado por vibração, o concreto autoadensável necessita de uma maior quantidade de finos, que contribui absorvendo água da mistura, auxiliando na garantia de uma viscosidade adequada que evite a segregação. O maior consumo de finos é acompanhado pela redução na quantidade de agregados empregados, especialmente do agregado graúdo. Portanto, as misturas de concreto autoadensável são constituídas por um maior volume de pasta e um menor volume de agregados quando comparadas às misturas de concreto convencional.

O concreto autoadensável se destaca pelas suas propriedades no estado fresco. Essas propriedades estão relacionadas com as características reológicas do material que definem o comportamento da fluidez ou a sua deformabilidade. Os primeiros estudos realizados sobre o tema confirmam que sua capacidade de autoadensabilidade é regida simultaneamente pela deformabilidade e resistência à segregação do concreto [13]. A deformabilidade depende essencialmente da tensão mínima necessária para o início do escoamento do concreto, o qual se caracteriza por uma tensão de escoamento e por uma moderada viscosidade plástica que impede o contato entre os agregados, evitando o bloqueio. A resistência à segregação, que representa a estabilidade da mistura, depende da moderada viscosidade plástica.

\subsection{Justificativa}

Apesar dos esforços e recentes avanços da indústria cerâmica nacional, um entrave importante que persiste em praticamente todos os arranjos produtivos locais de base mineral refere-se às perdas ao longo do processo produtivo. Quando os defeitos acontecem antes da queima, em que pesa a queda de produtividade, os produtos extrudados podem ser reprocessados. No entanto, o mesmo não acontece com as peças defeituosas após a 
queima que, por não ter até o momento nenhum aproveitamento em larga escala, vem sendo descartado junto aos empreendimentos cerâmicos.

Além das perdas econômicas, esse processo cumulativo de resíduos tem resultado em passivos ambientais de dimensões consideráveis nas aglomerações cerâmicas: estima-se que as perdas em produtos cerâmicos acabados se situam na faixa de 5\% a 10\%, representando um descarte de cacos cerâmicos de cerca de 1,5 a 3,0 milhões toneladas por ano no território paulista [17]. Com o intuito de reduzir os passivos ambientais gerados pelas indústrias de cerâmica vermelha, diminuir os custos operacionais e agregar valor aos produtos dessas empresas, têm sido desenvolvidas pesquisas contemplando o aproveitamento desses resíduos como adição mineral para produção de cimento Portland e concreto aplicados na construção civil. Esta aplicação foi considerada em função da sua composição química ser compatível com a composição química de outros materiais utilizados para a mesma finalidade.

$\mathrm{O}$ uso de adições minerais pode ser vantajoso em vários aspectos. Tecnicamente, o aumento da durabilidade é uma das razões mais relevantes para o uso de adições minerais na produção de cimentos e concretos. Há também justificativas econômicas, pois as adições minerais têm custos e preços menores quando comparadas ao clínquer e/ou ao cimento Portland. Há também as justificativas relacionadas com a sustentabilidade da cadeia de construção civil, quando considerada a redução do consumo de energia e da emissão de $\mathrm{CO}_{2}$ na produção de cimento e de concreto [18].

Como as propriedades fundamentais do concreto autoadensável dependem de elevada fluidez combinada com adequada coesão da mistura, na composição desses concretos é importante considerar a utilização de aditivos químicos (superplastificantes e/ou agentes modificadores de viscosidade) e de materiais finos (adições minerais e fílers), assim como agregados com dimensões menores e distribuição granulométrica contínua, obtendo-se uma mistura fluida, coesa e com microestrutura compacta, que resulta em elevado desempenho na aplicação. Assim, neste trabalho, a pozolana obtida a partir do resíduo da indústria de cerâmica vermelha foi utilizada para a produção de concreto autoadensável, sendo considerada tanto na produção do cimento composto quanto como adição ao concreto.

\section{MATERIAIS E MÉTODOS}

\subsection{Materiais constituintes}

\subsubsection{Produção da pozolana a partir do resíduo de cerâmica vermelha}

O resíduo de cerâmica vermelha (RCV), coletado em cacos, foi moído em laboratório considerando duas fases de moagem para a produção da pozolana [17]: inicialmente até totalmente passante na peneira de abertura de $0,85 \mathrm{~mm}$; e depois até totalmente passante na peneira de abertura de 0,075 $\mathrm{mm}$.

Na primeira fase da moagem, o material coletado foi britado por meio de um britador de mandíbula com capacidade para quebra dos cacos em frações com até $2 \mathrm{~cm}$ de diâmetro. Em seguida, o material foi seco em estufa até constância de massa. Na sequência, o material pré-moído e seco foi britado por meio de outro britador de mandíbula com abertura menor. O material obtido foi quarteado e colocado em tambor para homogeneização por rolagem.

A segunda fase da moagem foi realizada considerando o material obtido na primeira fase da moagem, utilizando-se um moinho de bolas. Para evitar a aglomeração das partículas do material, em função do seu pequeno diâmetro, foi utilizado um aditivo de moagem que atua nas cargas de superfície das partículas. $\mathrm{O}$ processo de moagem foi realizado ininterruptamente durante 2 horas e, ao término desse período, o material obtido foi avaliado e utilizado como adição mineral para a produção do cimento composto e do concreto autoadensável. O processo adotado na produção da pozolana obtida a partir de resíduos da indústria de cerâmica vermelha é resumido e ilustrado na Figura 1.

As características do material final, obtido após as duas etapas de moagem do RCV, são apresentadas nas Tabelas 1 e 2. Verifica-se que o processo de moagem adotado para a obtenção de pozolana, com vista à sua utilização como adição mineral para produção de cimento e de concreto, permitiu a obtenção de um material com propriedades químicas, físicas e mecânicas que o caracterizou como um material pozolânico e, assim, podendo ser utilizado para esta finalidade. 

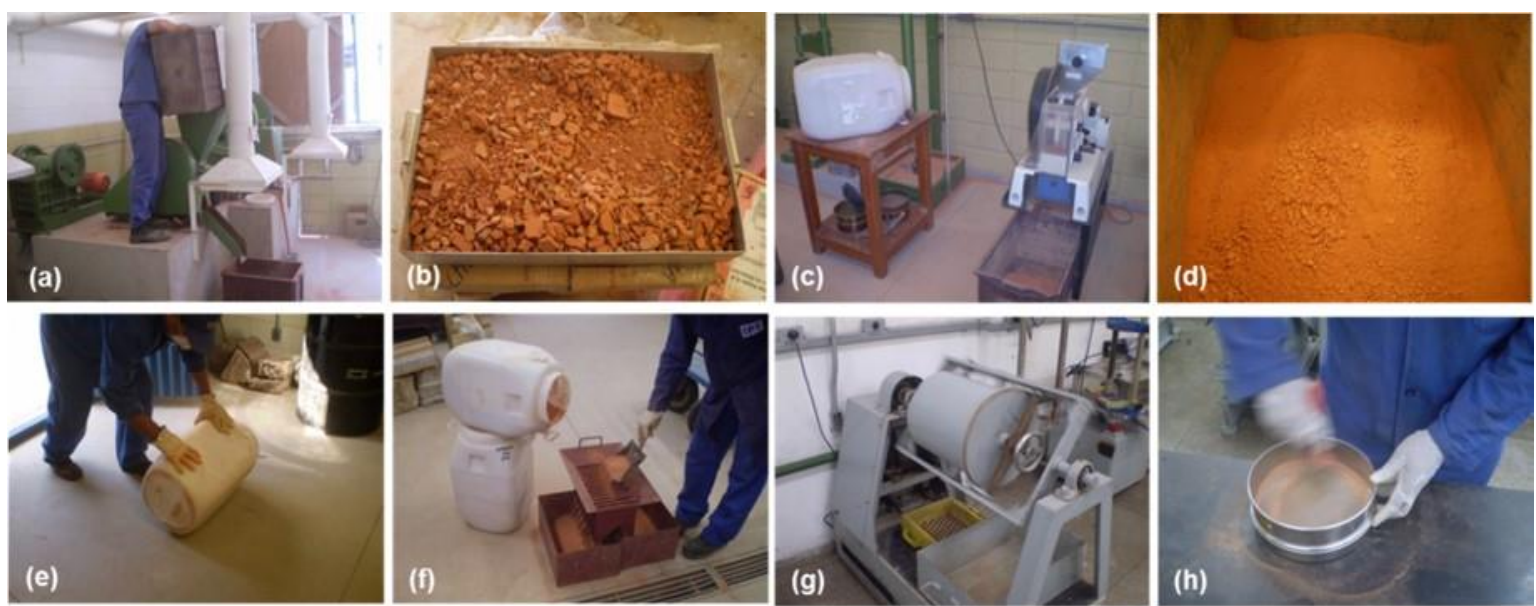

Figura 1: Produção da pozolana - Primeira fase da moagem dos cacos cerâmicos: (a) alimentação do britador de mandíbula, (b) material coletado após a primeira moagem, (c) britador de mandíbula com abertura menor, (d) material resultante das sucessivas moagens, (e) homogeneização e (f) quarteamento do material produzido. Segunda parte da moagem: (g) moagem em moinho de bolas e (h) peneiramento do material moído para verificação do atendimento à especificação.

Tabela 1: Resultados da análise química do material pozolânico obtido a partir do RCV.

\begin{tabular}{|c|c|c|}
\hline DETERMINAÇÕES & $\begin{array}{c}\text { LIMITES ESPECIFICADOS } \\
\text { NA NBR 12653:2014 [19] }\end{array}$ & RESULTADOS, EM \% \\
\hline Anidrido silícico $\left(\mathrm{SiO}_{2}\right)$ & ----- & 60,4 \\
\hline Óxido de alumínio $\left(\mathrm{Al}_{2} \mathrm{O}_{3}\right)$ & ----- & 21,8 \\
\hline Óxido férrico $\left(\mathrm{Fe}_{2} \mathrm{O}_{3}\right)$ & ----- & 8,17 \\
\hline Óxido de cálcio $(\mathrm{CaO})$ & ----- & 0,29 \\
\hline Óxido de magnésio $(\mathrm{MgO})$ & ----- & 0,29 \\
\hline Óxido de sódio $\left(\mathrm{Na}_{2} \mathrm{O}\right)$ & ---- & 0,14 \\
\hline Óxido de potássio $\left(\mathrm{K}_{2} \mathrm{O}\right)$ & ----- & 1,60 \\
\hline Óxido de manganês $\left(\mathrm{Mn}_{2} \mathrm{O}_{3}\right)$ & ----- & 0,08 \\
\hline Óxido de titânio $\left(\mathrm{TiO}_{2}\right)$ & ----- & 1,88 \\
\hline $\mathrm{SiO}_{2}+\mathrm{Al}_{2} \mathrm{O}_{3}+\mathrm{Fe}_{2} \mathrm{O}_{3}$ & $\geq 70 \%$ & 90,4 \\
\hline Anidrido sulfúrico $\left(\mathrm{SO}_{3}\right)$ & $\leq 4 \%$ & $<0,10$ \\
\hline Perda ao fogo & $\leq 10 \%$ & 2,37 \\
\hline Equivalente alcalino em $\mathrm{Na}_{2} \mathrm{O}$ & ----- & 1,19 \\
\hline Álcalis disponíveis em $\mathrm{Na}_{2} \mathrm{O}$ & $\leq 1,5 \%$ & ----- \\
\hline
\end{tabular}

Tabela 2: Resultados dos ensaios físicos e mecânicos do material pozolânico obtido a partir do RCV.

\begin{tabular}{c|c|c|c|c|c}
\hline \multicolumn{3}{c|}{ MASSA ESPECÍFICA $\left(\mathbf{g} / \mathbf{c m}^{3}\right)$} & \multicolumn{3}{c}{ ÁREA SUPERFICIAL ESPECÍFICA (cm²/g) } \\
\hline \multicolumn{3}{c|}{2,70} & \multicolumn{3}{c}{12.750} \\
\hline \multicolumn{3}{c}{ ÍNDICE DE ATIVIDADE POZOLÂNICA COM CAL } \\
\hline \multicolumn{3}{c|}{ Resistência à compressão (MPa) } \\
CP 01 & CP02 & CP 03 & Média & máximo (\%) & NBR 12653:2014 [19] \\
\hline 6,8 & 7,4 & 7,4 & 7,2 & 5,6 & $\geq 6 \mathrm{MPa}$ \\
\hline
\end{tabular}




\subsubsection{Produção do cimento composto com pozolana}

No Brasil, dentre os cimentos normalizados e disponíveis para comercialização na construção civil, a utilização do RCV, moído e peneirado até totalmente passante na peneira com abertura de $0,075 \mathrm{~mm}$, como uma adição mineral é possível para a produção de cimento Portland composto com pozolana (CPII Z) e de cimento Portland pozolânico (CPIV).

No presente estudo, foi considerada a produção do CPII Z no laboratório [20]. Para isso, a pozolana obtida a partir do RCV foi combinada com um cimento Portland de alta resistência inicial (CPV ARI) disponível comercialmente, utilizando a proporção de $12 \%$ de pozolana e $88 \%$ de CPV ARI, em massa. O CPV ARI foi selecionado por conter o maior teor de clínquer dentre os cimentos disponíveis e, assim, consistir em um cimento "mais puro" em termos de adições. A fim de obter uma mistura homogênea entre os materiais, a pozolana e o CPV ARI foram misturados a seco em um homogeneizador em Y durante 20 minutos. O CPII Z produzido no laboratório foi posteriormente utilizado para a produção do concreto autoadensável.

\subsubsection{Outros materiais}

Para a produção do concreto autoadensável (CAA), além da pozolana obtida a partir do RCV e do cimento composto com pozolana produzido no laboratório (CPII Z-LAB), foram utilizados outros materiais, a saber:

- cimento Portland composto com pozolana (CPII Z 32), disponível comercialmente;

- $\quad$ agregado miúdo: areia fina e areia média quartzosas, provenientes de cava de rio;

- agregado graúdo: brita de origem basáltica, classificada como brita 0 ;

- $\quad$ aditivo químico: superplastificante à base de policarboxilato (AdvaCast®585);

- $\quad$ água fornecida pela rede de distribuição local.

As propriedades químicas, físicas e mecânicas dos cimentos, tanto o produzido no laboratório quanto o disponível comercialmente, são apresentadas nas Tabelas 3 e 4 . As propriedades físicas dos agregados miúdo e graúdo são apresentadas na Tabela 5, enquanto sua distribuição granulométrica é apresentada na Figura 2 .

Tabela 3: Resultados dos ensaios químicos dos cimentos compostos considerados no estudo.

\begin{tabular}{|c|c|c|c|}
\hline \multirow{2}{*}{ DETERMINAÇÕES } & \multirow{2}{*}{$\begin{array}{c}\text { LIMITES DA NBR } \\
\text { 11578:1991 [21], EM \% }\end{array}$} & \multicolumn{2}{|c|}{ RESULTADOS, EM \% } \\
\hline & & CPII Z 32 & CPII Z-LAB \\
\hline Perda ao fogo $(\mathrm{PF})$ & $\leq 6,5$ & 3,82 & 3,63 \\
\hline Anidrido silícico $\left(\mathrm{SiO}_{2}\right)$ & --- & 23,4 & 24,3 \\
\hline Óxido de cálcio $(\mathrm{CaO})$ & --- & 54,9 & 54,2 \\
\hline Óxido de magnésio (MgO) & $\leq 6,5$ & 2,05 & 2,35 \\
\hline Óxido férrico $\left(\mathrm{Fe}_{2} \mathrm{O}_{3}\right)$ & --- & 3,29 & 3,06 \\
\hline Óxido de alumínio $\left(\mathrm{Al}_{2} \mathrm{O}_{3}\right)$ & --- & 6,52 & 5,65 \\
\hline Anidrido sulfúrico $\left(\mathrm{SO}_{3}\right)$ & $\leq 4,0$ & 3,67 & 3,70 \\
\hline Óxido de sódio $\left(\mathrm{Na}_{2} \mathrm{O}\right)^{(1)}$ & --- & 0,40 & 0,40 \\
\hline Óxido de potássio $\left(\mathrm{K}_{2} \mathrm{O}\right)^{(1)}$ & --- & 0,91 & 0,89 \\
\hline Equivalente alcalino $\left(\mathrm{em} \mathrm{Na}_{2} \mathrm{O}\right)^{(2)}$ & --- & 1,00 & 0,98 \\
\hline Sulfeto $\left(\mathrm{S}^{2-}\right)$ & --- & n.d. & n.d. \\
\hline Óxido de cálcio livre $(\mathrm{CaO})$ & --- & 1,30 & 1,36 \\
\hline Resíduo insolúvel (RI) & $\leq 16,0$ & 11,9 & 11,8 \\
\hline Anidrido carbônico $\left(\mathrm{CO}_{2}\right)$ & $\leq 5,0$ & 1,97 & 1,89 \\
\hline Pozolana $^{(3)}$ & $6-14$ & 11,9 & 12,8 \\
\hline Material carbonático ${ }^{(4)}$ & $0-10$ & 4,47 & 5,18 \\
\hline \multicolumn{4}{|c|}{$\begin{array}{l}\text { Notas: n.d. = não detectado; }{ }^{(1)} \text { Determinado por absorção atômica; }{ }^{(2)} \text { Equivalente alcalino }\left(\mathrm{em} \mathrm{Na}_{2} \mathrm{O}\right)=\% \mathrm{Na}_{2} \mathrm{O}+0,658 \times \% \mathrm{~K}_{2} \mathrm{O} ;{ }^{(3)} \\
\text { Estima-se o teor de pozolana pelo teor resíduo insolúvel (RI) }(1: 50) ;{ }^{(4)} \text { Valor estimado pelo seguinte cálculo estequiométrico: } \% \\
\mathrm{CaCO}_{3}=\% \mathrm{CO}_{2} \times 2,27 .\end{array}$} \\
\hline
\end{tabular}


Tabela 4: Resultados dos ensaios físicos e mecânicos dos cimentos compostos considerados no estudo.

\begin{tabular}{|c|c|c|c|}
\hline \multirow{2}{*}{ CARACTERÍSTICAS FÍSICAS } & \multicolumn{2}{|c|}{ RESULTADOS } & \multirow{2}{*}{$\begin{array}{c}\text { LIMITES DA NBR 11578:1991 } \\
\text { [21] }\end{array}$} \\
\hline & CPII Z 32 & CPII Z-LAB & \\
\hline Massa específica $\left(\mathrm{g} / \mathrm{cm}^{3}\right)$ & 3,02 & 3,02 & --- \\
\hline Área superficial específica $\left(\mathrm{m}^{2} / \mathrm{kg}\right)$ & 413 & 608 & $\begin{array}{l}\text { Classe } 25 \geq 240 \mathrm{~m}^{2} / \mathrm{kg} \\
\text { Classe } 32 \geq 260 \mathrm{~m}^{2} / \mathrm{kg} \\
\text { Classe } 40 \geq 280 \mathrm{~m}^{2} / \mathrm{kg}\end{array}$ \\
\hline $\begin{array}{c}\text { Água para pasta normal } \\
\text { (\% massa do cimento) }\end{array}$ & 25,5 & 32,7 & --- \\
\hline Início de pega (min) & 315 & 185 & $\geq 60 \mathrm{~min}$ \\
\hline Fim de pega $(\min )$ & 375 & 270 & $\leq 600 \mathrm{~min}$ \\
\hline Expansibilidade a frio $(\mathrm{mm})$ & 0,5 & 1,0 & $\leq 5,0 \mathrm{~mm}$ \\
\hline Expansibilidade a quente (mm) & 0,5 & 0,0 & $\leq 5,0 \mathrm{~mm}$ \\
\hline \multicolumn{4}{|c|}{ Resistência à compressão (MPa) } \\
\hline 3 dias & 22,4 & 29,4 & $\begin{array}{l}\text { Classe } 25 \geq 8,0 \mathrm{MPa} \\
\text { Classe } 32 \geq 10,0 \mathrm{MPa} \\
\text { Classe } 40 \geq 15,0 \mathrm{MPa}\end{array}$ \\
\hline 7 dias & 26,5 & 38,3 & $\begin{array}{l}\text { Classe } 25 \geq 15,0 \mathrm{MPa} \\
\text { Classe } 32 \geq 20,0 \mathrm{MPa} \\
\text { Classe } 40 \geq 25,0 \mathrm{MPa}\end{array}$ \\
\hline 28 dias & 35,1 & 47,6 & $\begin{array}{l}\text { Classe } 25 \geq 25,0 \mathrm{MPa} \\
\text { Classe } 32 \geq 32,0 \mathrm{MPa} \\
\text { Classe } 40 \geq 40,0 \mathrm{MPa}\end{array}$ \\
\hline
\end{tabular}

Tabela 5: Propriedades físicas dos agregados utilizados no estudo.

\begin{tabular}{c|c|c|c}
\hline \multirow{2}{*}{ PROPRIEDADES } & \multicolumn{3}{|c}{ MATERIAIS } \\
\cline { 2 - 4 } & AREIA FINA & AREIA MÉDIA & BRITA 0 \\
\hline Massa específica $\left(\mathrm{g} / \mathrm{cm}^{3}\right)$ & 2,62 & 2,64 & 2,88 \\
\hline Massa unitária $\left(\mathrm{g} / \mathrm{cm}^{3}\right)$ & 1,47 & 1,49 & 1,51 \\
\hline Absorção de água $(\%)$ & 0,46 & 1,41 & 0,57 \\
\hline Módulo de finura & 1,15 & 2,37 & 5,57 \\
\hline Dimensão máxima característica $(\mathrm{mm})$ & 0,60 & 4,75 & 9,50 \\
\hline
\end{tabular}




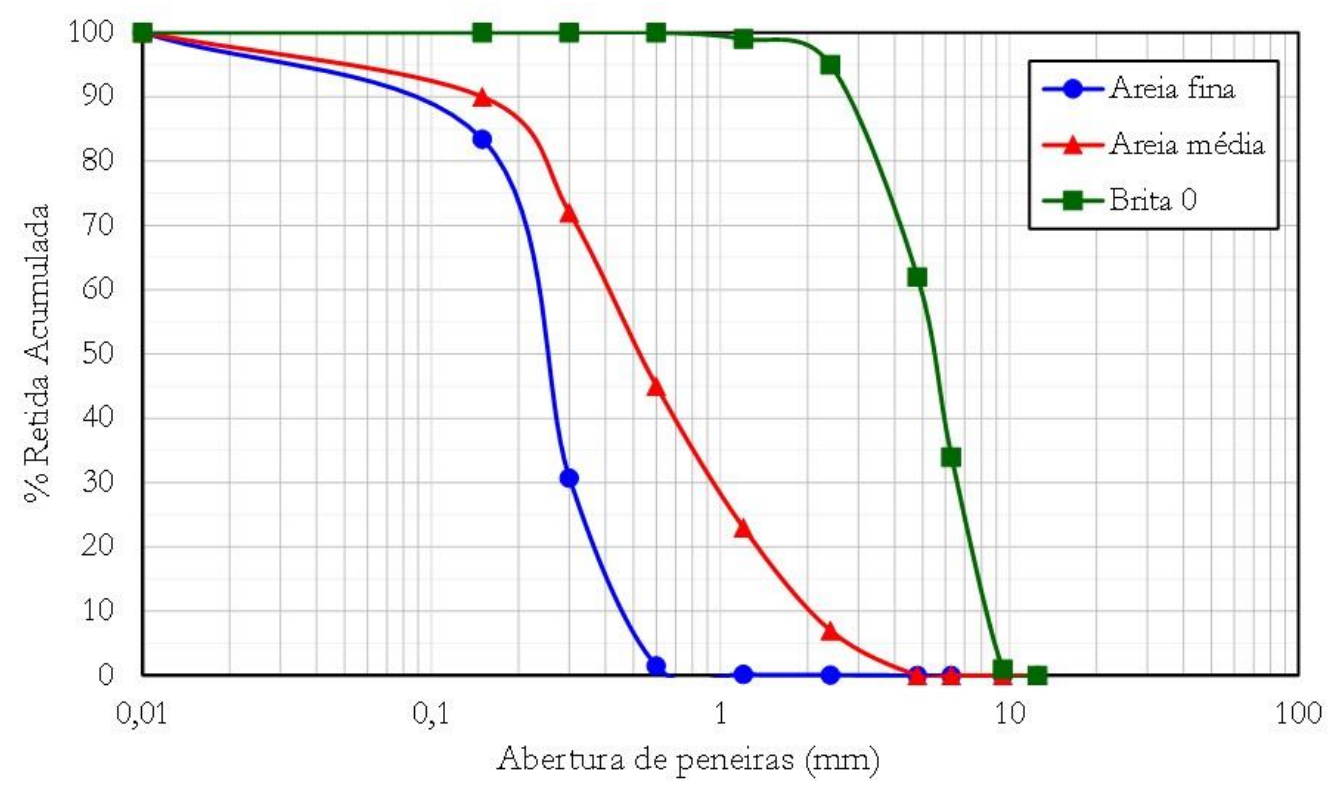

Figura 2: Distribuição granulométrica dos agregados utilizados no estudo.

\subsection{Produção do concreto autoadensável}

A pozolana obtida a partir do RCV foi utilizada para a produção de concreto autoadensável, sendo considerada tanto na produção de cimento composto quanto como adição ao concreto. Assim, foram produzidas duas misturas de CAA de mesmo traço, alterando apenas o cimento constituinte, sendo uma produzida com o CPII Z 32 disponível comercialmente (referência), e uma com o cimento composto produzido no laboratório (CPII Z-LAB), identificadas no presente trabalho pelas siglas CAA-REF e CAA-LAB, respectivamente.

O método de dosagem adotado para o desenvolvimento dos concretos foi o proposto por GOMES [22], que consiste em um procedimento experimental para a obtenção de traços de CAA de alta resistência, considerando a otimização da composição da pasta e do esqueleto granular separadamente. A composição final do CAA é obtida buscando-se o teor de pasta necessário para que o concreto apresente parâmetros de fluidez e viscosidade pré-estabelecidos. Assim, o método é executado em três fases: obtenção da composição da pasta, determinação da proporção da mistura dos agregados e, por fim, determinação do teor mínimo de pasta, que consiste na determinação da composição final do concreto autoadensável.

A primeira fase, que consiste na otimização da composição da pasta, abrange a determinação dos teores ótimos de aditivo superplastificante e materiais finos. Esta fase é realizada em duas etapas: a primeira consiste na determinação do teor de superplastificante em relação à massa de cimento $(\mathrm{SP} / \mathrm{c})$, considerando diferentes teores de materiais finos na composição da pasta, por meio do ensaio do funil de Marsh [23]; e a segunda na determinação da relação ótima de materiais finos/cimento (f/c), considerando o teor ótimo de aditivo superplastificante definido na primeira etapa, por meio do ensaio de miniabatimento (ensaio de Kantro) [24].

O ponto de saturação do aditivo superplastificante foi determinado para cada combinação de cimento e pozolana adotando-se o método AFREM [25]. Neste método, o ponto de saturação (teor ótimo) do aditivo é considerado como o teor de aditivo em que uma reta com inclinação de 2:5 tangencia a curva "logaritmo do tempo de escoamento versus teor de aditivo". De acordo com os autores do método, a escolha desta inclinação é arbitrária, tendo sido adotada em função das proporções adequadas obtidas a partir da mesma.

Após a determinação do teor ótimo de aditivo superplastificante para cada composição de pasta de cimento e pozolana, foi realizado o ensaio de miniabatimento de tronco de cone [24] para determinação da relação materiais finos/cimento. Este ensaio consistiu na determinação da combinação ideal de pozolana/cimento da pasta, considerando os parâmetros de espalhamento e tempo de espalhamento para a pasta atingir o diâmetro de $115 \mathrm{~mm}$, fixados em $(180 \pm 10) \mathrm{mm}$ e $(3 \pm 1) \mathrm{s}$, respectivamente [22].

Assim, os ensaios nas pastas permitem obter as respectivas relações de SP/c e f/c que geram pastas com características adequadas à obtenção de misturas de concreto autoadensável com elevada fluidez, moderada coesão e sem segregação.

O esqueleto granular, definido como a composição de agregados miúdo e graúdo que constituem o 
concreto, é obtido considerando-se a densidade da mistura de agregados com menor teor de vazios, apresentando, consequentemente, uma composição que necessita de um mínimo volume de pasta para assegurar a viscosidade e a fluidez do concreto. Este fator é fundamental para a escolha do método aplicado neste trabalho, no qual se faz necessário um concreto compacto, porém com viscosidade e fluidez adequadas para o CAA.

A composição do esqueleto granular consistiu na determinação do melhor empacotamento entre as partículas de agregados que compõem as misturas de CAA, mediante a determinação da composição ideal entre eles. A composição ideal entre os agregados foi determinada por meio do ensaio de massa unitária no estado solto [26] considerando diferentes combinações de agregados, ou seja, diferentes proporções entre os agregados miúdo e graúdo, sendo considerada como ideal a composição que apresentar maior massa unitária e, consequentemente, menor índice de vazios.

Uma vez determinadas as composições da pasta e do esqueleto granular, o último parâmetro necessário para definir a composição do CAA é o volume de pasta, que é determinado como o teor de vazios encontrado entre os agregados, mais um incremento que promove a dispersão dos mesmos [13], ou seja, a última etapa do estudo de dosagem consiste na determinação do volume mínimo de pasta capaz de envolver e conferir as características reológicas necessárias ao concreto no estado fresco.

O volume adequado de pasta é determinado a partir dos ensaios para determinação das propriedades de autoadensabilidade do concreto no estado fresco, isto é, os ensaios de espalhamento pelo cone de Abrams [27] e anel J [28], Caixa L [29], Funil V [30] e coluna de segregação [31], a fim de atender e garantir o preenchimento, a fluidez e a estabilidade da mistura.

Para a produção das misturas de CAA, considerou-se a utilização dos agregados na condição saturada superfície seca e, dessa maneira, a quantidade de água necessária para sua saturação foi adicionada com base nos respectivos coeficientes de absorção. Assim, a composição das misturas por $\mathrm{m}^{3}$ de concreto foi obtida considerando-se a hipótese de que o teor de ar da pasta fosse mantido no concreto e, então, que o volume de concreto seria dado pela somatória dos volumes de pasta, agregado miúdo e agregado graúdo [22].

Os parâmetros de autoadensabilidade especificados para os concretos produzidos neste estudo foram definidos de acordo as recomendações da NBR 15823-1:2010 [32], considerando a aplicação desses concretos em elementos estruturais densamente armados:

- classe de espalhamento SF2, com valor de espalhamento variando entre $660 \mathrm{~mm}$ e $750 \mathrm{~mm}$;

- classe de viscosidade plástica aparente VS2, com tempo de escoamento t500 superior a 2 s, e classe VF1, com tempo de escoamento medido no funil V menor que $9 \mathrm{~s}$;

- classe de habilidade passante PL1, com a diferença entre os diâmetros de espalhamento obtidos sem e com o anel $\mathbf{J}$ variando entre $25 \mathrm{~mm}$ e $50 \mathrm{~mm}$, e classe PJ1, com razão de bloqueio medida com o auxílio da caixa L igual ou maior que 0,80 ;

- classe de resistência à segregação SR2, com resistência à segregação menor ou igual a $15 \%$ medida na coluna de segregação.

\subsection{Avaliação das propriedades do concreto autoadensável no estado endurecido}

Além das propriedades de autoadensabilidade no estado fresco, foram avaliadas as propriedades físicas e mecânicas dos concretos quando do estado endurecido. A avaliação das propriedades físicas dos concretos consistiu na determinação da massa específica, absorção de água e índice de vazios [33], enquanto a avaliação das propriedades mecânicas consistiu na determinação da sua resistência à compressão [34].

Para a determinação das propriedades no estado endurecido, foram moldados corpos de prova cilíndricos, com $100 \mathrm{~mm}$ de diâmetro e $200 \mathrm{~mm}$ de altura. Após 24 h da moldagem, os corpos de prova foram desmoldados e submetidos à cura úmida por imersão em água saturada com cal, onde permaneceram até as idades de ensaio. O ensaio para determinação da resistência à compressão foi realizado nas idades de 7 e 28 dias, e os ensaios físicos foram realizados apenas aos 28 dias de idade. Para a realização do ensaio mecânico, as superfícies dos corpos de prova foram capeadas com uma mistura de enxofre para regularização da superfície de ensaio.

\section{RESULTADOS E DISCUSSÕES}

\subsection{Definição dos traços de concreto autoadensável}

Inicialmente, a relação água/cimento foi fixada em 0,45 para as duas misturas de CAA. A partir desta infor- 
mação, para determinação da composição da pasta, primeiramente foi determinado o ponto de saturação (teor ótimo) do aditivo superplastificante para cada tipo de cimento. Para isso, foram utilizadas pastas de cimento com adição de $10 \%, 15 \%, 20 \%$ e $25 \%$ de pozolana obtida a partir de RCV e, para cada uma dessas combinações, foi determinado o ponto de saturação do aditivo, medindo-se o tempo do escoamento de um determinado volume de pasta através do cone de Marsh [23], conforme ilustrado na Figura 3.
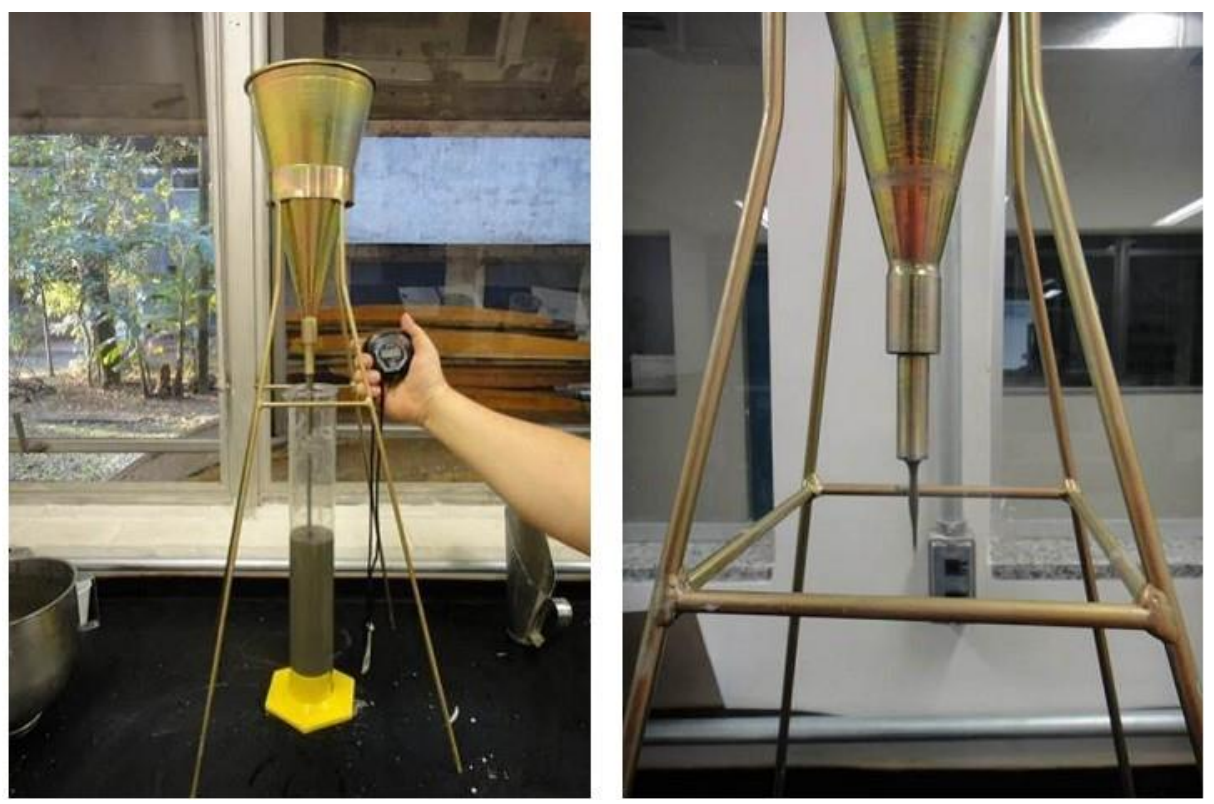

Figura 3: Ensaio de índice de fluidez em pastas de cimento, paradeterminação do teor ótimo de aditivo superplastificante.

Uma vez definido o teor ótimo de aditivo superplastificante para cada composição de pasta de cimento e pozolana, foi realizado o ensaio de miniabatimento de tronco de cone [24] para determinação da combinação ideal de pozolana/cimento da pasta, considerando parâmetros de espalhamento e tempo de espalhamento (Figura 4).
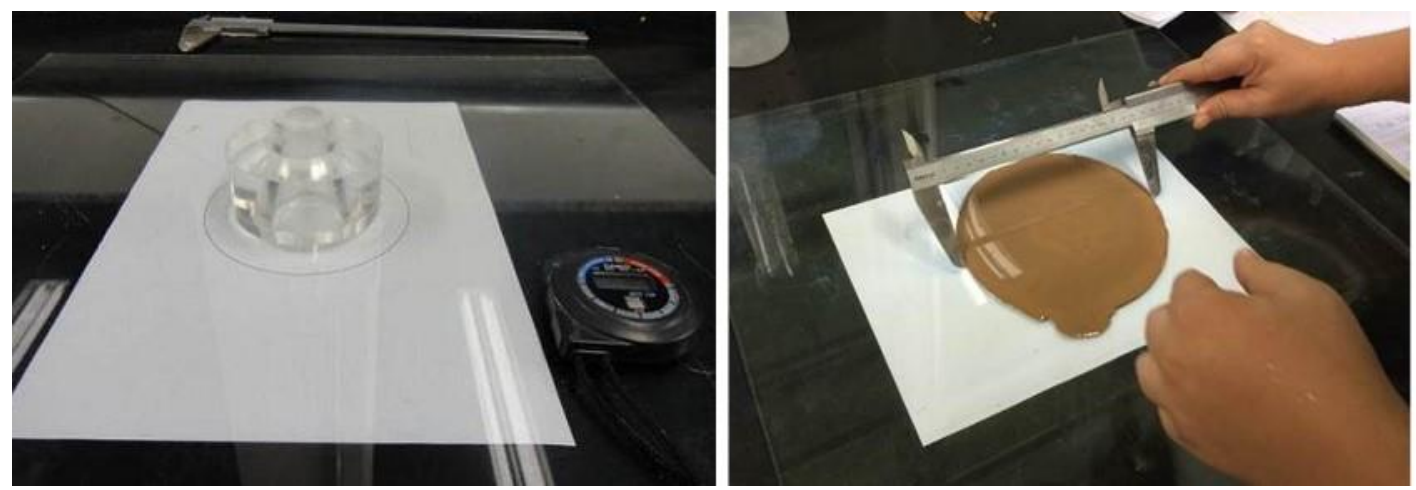

Figura 4: Ensaio de miniabatimento de tronco cone em pastas de cimento.

Assim, considerando-se os critérios estabelecidos para as pastas de cimento e pozolana, a partir dos ensaios de funil de Marsh e de miniabatimento, o estudo para determinação da composição da pasta definiu as seguintes matrizes para as duas misturas de CAA a serem produzidas:

- $\quad$ pasta produzida com CPII Z 32: relação água/cimento de 0,45 , teor de pozolana de $20 \%$, e teor ótimo de aditivo superplastificante de $0,28 \%$ em relação à massa de cimento;

- $\quad$ pasta produzida com CPII Z-LAB: relação água/cimento de 0,45 , teor de pozolana de $20 \%$, e teor ótimo de aditivo superplastificante de $0,62 \%$ em relação à massa de cimento.

Como todos os materiais constituintes das misturas de CAA são os mesmos, com exceção do cimento, verifi- 
ca-se que a pasta produzida com o CPII Z-LAB demandou um maior teor de aditivo superplastificante para atender às propriedades de autoadensabilidade pré-estabelecidas do que a pasta produzida com CPII Z 32. A maior demanda de aditivo pela pasta produzida com o CPII Z-LAB está associada à maior área superficial específica do cimento constituinte da mistura, resultando no aumento da quantidade de aditivo necessária para atender às especificações no estado fresco, uma vez que a relação água/cimento foi mantida constante. Cabe ressaltar que o teor de aditivo superplastificante é apresentado considerando o teor de sólidos do aditivo em relação à massa de cimento.

Como para a composição do esqueleto granular foram consideradas duas areias como agregado miúdo, primeiramente foi determinada a composição ideal entre elas. Assim, a composição ideal para o agregado miúdo foi realizada considerando a combinação das areias fina e média, sendo determinada como ideal a composição composta de $40 \%$ de areia fina e $60 \%$ de areia média. Na sequência, a composição considerada ideal para o agregado miúdo foi combinada com o agregado graúdo (brita 0) em diferentes frações para determinar a composição ideal do esqueleto granular das misturas de CAA. A composição ideal do esqueleto granular, adotada para a produção das duas misturas de CAA, foi de $40 \%$ de agregado miúdo e $60 \%$ de agregado graúdo.

A composição final do CAA foi determinada variando-se o volume de pasta da mistura entre $38 \%$ e $42 \%$, sendo determinadas as propriedades de autoadensabilidade para cada mistura, a fim de obter o concreto com as propriedades pré-estabelecidas com a menor quantidade de pasta possível. Para os teores de pasta avaliados, o teor que se mostrou mais adequado para a produção do CAA foi $40 \%$, uma vez que as duas misturas (CAA-REF e CAA-LAB) produzidas com esse volume de pasta apresentaram as propriedades de autoadensabilidade pré-estabelecidas, sem evidência de exsudação e segregação (Tabela 6). $\mathrm{O}$ aspecto geral dos concretos produzidos com este volume de pasta é apresentado na Figura 5.

Tabela 6: Resultados dos ensaios do CAA no estado fresco.

\begin{tabular}{|c|c|c|c|}
\hline CONCRETO & CAA-REF & CAA-LAB & LIMITES DA NBR 15823-1:2010 [32] \\
\hline Volume de pasta & $40 \%$ & $40 \%$ & Classe SF2, VS2, PJ1, VF1, SR2, PL2 \\
\hline Espalhamento (mm) & 665 & 700 & 660 a $750 \mathrm{~mm}$ \\
\hline $\mathrm{T}_{500}(\mathrm{~s})$ & $2 " 80$ & $3 ” 10$ & $>2 ”$ \\
\hline $\mathrm{TJ}_{500}(\mathrm{~s})$ & $2 " 92$ & $2 " 55$ & --- \\
\hline Espalhamento J (mm) & 652 & 670 & --- \\
\hline $\mathrm{Tv}$ & 3" 80 & $5 " 27$ & $<9 "$ \\
\hline $\mathrm{Tv}_{5}$ & $3 ” 55$ & 6” 02 & $<9 "$ \\
\hline Segregação (\%) & 13 & 15 & $\leq 15 \%$ \\
\hline Caixa L (H2/H1) & 0,89 & 0,96 & $>0,80$ \\
\hline
\end{tabular}
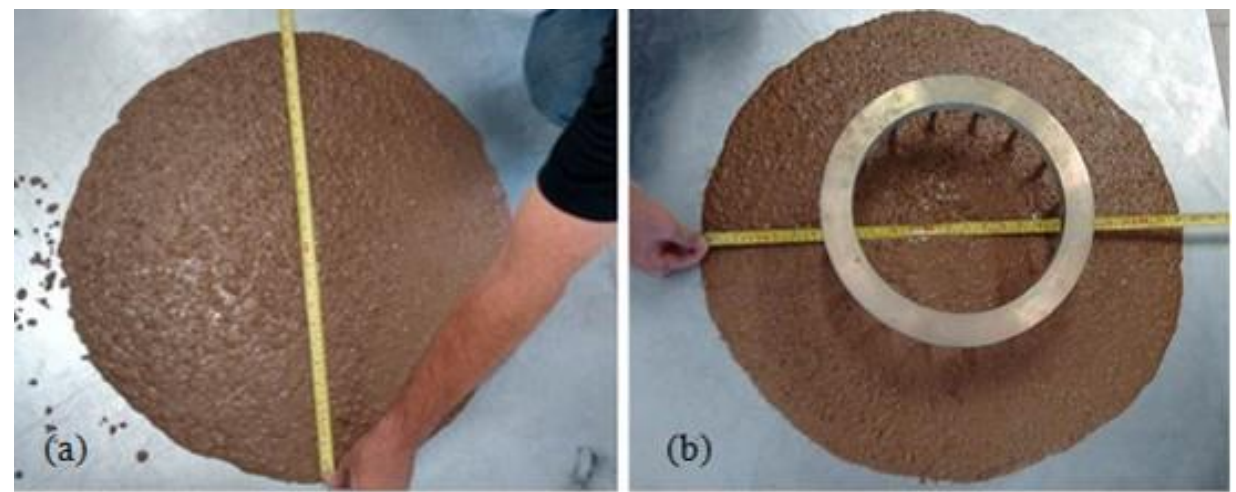

Figura 5: Aspecto geral dos concretos produzidos: (a) CAA-REF; e (b) CAA-LAB.

Para o CAA-REF, o teor ótimo de aditivo de $0,28 \%$, obtido na etapa de determinação da composição 
da pasta, foi o teor ideal para que a mistura de concreto apresentasse fluidez e coesão adequadas, sem evidência de exsudação e segregação. Já para o CAA-LAB, o teor ótimo de aditivo de $0,62 \%$, determinado quando do estudo da composição da pasta, resultou em um espalhamento superior à faixa pré-estabelecida e foi verificada exsudação na amostra de concreto. Dessa maneira, foi necessário ajustar o teor de aditivo dessa mistura de concreto, resultando em um teor de $0,42 \%$ em relação à massa de cimento e, então, obtendo-se um CAA com as propriedades de autoadensabilidade pré-estabelecidas, sem exsudação e segregação. Assim, as misturas de CAA produzidas com o CPII Z 32 e CPII Z-LAB são compostas por um volume de pasta de $40 \%$, resultando nos consumos de materiais apresentados na Tabela 7.

Tabela 7: Composição final das misturas de CAA:consumo dos materiais constituintes.

\begin{tabular}{c|c|c}
\hline CONCRETO & CAA-REF & CAA-LAB \\
\hline Relação água/cimento & 0,45 & $20 \%$ \\
\hline Teor de pozolana & $20 \%$ & $0,42 \%$ \\
\hline Teor de superplastificante & $0,28 \%$ & $40 \%$ \\
\hline Volume de pasta & $40 \%$ & 960 \\
\hline MATERIAIS CoNSTITUINTES & CONSUMO (kg/m $\mathbf{m}^{3}$ DE CONCRETO) \\
\hline Brita 0 & 960 & 384 \\
\hline Areia média & 384 & 256 \\
\hline Areia fina & 256 & 463 \\
\hline Cimento & 463 & 93 \\
\hline Pozolana de RCV & 93 & 217 \\
\hline Água & 217 & 1,945 \\
\hline Superplastificante & 1,298 & \\
\hline
\end{tabular}

Nota: teor de superplastificante considerado em termos de teor de sólidos do aditivo em relação à massa de cimento.

\subsection{Avaliação das propriedades do concreto autoadensável no estado endurecido}

\subsubsection{Massa específica, absorção de água e índice de vazios}

As propriedades físicas determinadas no estado endurecido, isto é, massa específica, absorção de água e índice de vazios foram determinados em corpos de prova cilíndricos, conforme diretrizes da NBR 9778:2005 [33]. Os ensaios físicos foram realizados apenas aos 28 dias de idade, sendo os resultados apresentados na Tabela 8 correspondentes à média dos resultados de três corpos de prova ensaiados para cada mistura de concreto.

Tabela 8: Resultados dos ensaios físicos obtidos para os CAA produzidos.

\begin{tabular}{c|c|c|c}
\hline CONCRETO & ABSORÇÃO DE ÁGUA(\%) & ÍNDICE DE VAZIOS(\%) & MASSA ESPECÍFICA (g/cm $\left.\mathbf{c}^{3}\right)$ \\
\hline CAA-REF & 5,1 & 11,4 & 2,56 \\
\hline CAA-LAB & 4,1 & 9,2 & 2,51 \\
\hline
\end{tabular}

Os resultados dos ensaios físicos (Tabela 8) mostram que o CAA-LAB apresenta menor absorção de água e índice de vazios e, consequentemente, maior massa específica em relação ao CAA-REF. Como todos os materiais constituintes das duas misturas de CAA são os mesmos, com exceção do cimento, pode-se associar este comportamento com a maior área superficial específica do CPII Z-LAB constituinte do CAA-LAB, 
resultando em um maior empacotamento entre os materiais granulares constituintes da mistura e, assim, em uma matriz mais densa quando no estado endurecido.

De acordo com a literatura [35], para um concreto ser durável, sua absorção de água deve ser, no máximo, de 4,2\%, enquanto uma absorção máxima de 6,3\% é especificada para um concreto normal; acima de $6,3 \%$, o concreto é considerado deficiente em termos de durabilidade. No caso do índice de vazios, os limites estabelecidos para um concreto ser considerado durável ou normal são, respectivamente, 10\% e 15\%; acima de $15 \%$, o concreto é considerado deficiente em termos de durabilidade. Dessa maneira, com base nesses limites, o CAA-LAB pode ser considerado um concreto durável, enquanto o CAA-REF pode ser considerado como normal em termos de durabilidade.

\subsubsection{Resistência à compressão}

A resistência à compressão de ambas as misturas de CAA foi determinada em corpos de prova cilíndricos, conforme diretrizes da NBR 5739:2007 [34]. Os ensaios mecânicos foram realizados nas idades de 7 e 28 dias, sendo os resultados apresentados na Tabela 9 correspondentes à média dos resultados de três corpos de prova ensaiados para cada mistura de concreto.

Tabela 9: Resultados dos ensaios mecânicos dos CAA produzidos.

\begin{tabular}{c|c|c|c}
\hline \multirow{2}{*}{ IDADE } & \multirow{2}{*}{ RESULTADOS } & \multicolumn{2}{|c}{ RESISTENCIA A COMPRESSÃO (MPa) } \\
\cline { 3 - 4 } & & CAA-REF & CAA-LAB \\
\hline \multirow{3}{*}{7 dias } & Média & 37,8 & 51,6 \\
\cline { 2 - 4 } & Desvio padrão & 0,9 & 1,2 \\
\hline \multirow{2}{*}{28 dias } & Média & 50,1 & 66,0 \\
\cline { 2 - 4 } & Desvio padrão & 2,5 & 0,3 \\
\hline
\end{tabular}

A partir dos resultados obtidos nos ensaios mecânicos (Tabela 9), verifica-se que ambas as misturas de CAA produzidas podem ser consideradas de alta resistência, por apresentarem valores de resistência à compressão superior a $50 \mathrm{MPa}$ aos 28 dias de idade. Além disso, verifica-se que o CAA-LAB apresentou valores de resistência à compressão superiores ao CAA-REF nas duas idades de ensaio.

Novamente é possível observar o efeito do CPII Z-LAB sobre o comportamento do concreto quando do estado endurecido, uma vez que a única diferença na composição das misturas é o tipo de cimento utilizado. Assim, o melhor desempenho mecânico do CAA-LAB pode ser associado à maior área superficial específica do CPII Z-LAB constituinte do concreto, resultando em uma maior reatividade e em um maior empacotamento entre os materiais granulares e, assim, em maiores resistências já nas primeiras idades e em uma matriz mais densa quando no estado endurecido.

\section{CONCLUSÕES}

Como todos os materiais constituintes das duas misturas de CAA são os mesmos, com exceção do cimento, pode-se associar as diferenças de comportamento tanto no estado fresco quanto no estado endurecido ao tipo de cimento constituinte das misturas.

Inicialmente, quando da definição dos traços de CAA, pode-se verificar que a pasta produzida com cimento composto com pozolana produzido no laboratório (CPII Z-LAB) demandou um teor ótimo de aditivo superplastificante consideravelmente superior àquela produzida com cimento composto com pozolana disponível comercialmente (CPII Z 32). Este fato deve-se à maior finura associada à maior área superficial específica do cimento produzido no laboratório em relação ao cimento comercial, uma vez que a relação água/cimento foi mantida constante para as duas misturas.

Em relação às propriedades de autoadensabilidade, as duas misturas de CAA apresentaram resultados satisfatórios, atendendo aos requisitos estabelecidos previamente quanto às classes de espalhamento, viscosidade plástica aparente, habilidade passante e resistência à segregação.

Os resultados dos ensaios físicos e mecânicos, realizados nas misturas de CAA quando do estado endurecido, demonstram a influência do tipo de cimento sobre o comportamento dos concretos. Este fato é evidenciado pelos resultados dos índices físicos, que apontam o CAA-LAB como um material mais denso, com 
menos poros permeáveis (menor índice de vazios) em relação ao CAA-REF. Da mesma forma, os resultados dos ensaios mecânicos demonstram que a resistência à compressão do CAA-LAB é superior à do CAA-REF, em todas as idades de ensaio. $\mathrm{O}$ comportamento observado a partir dos resultados dos ensaios físicos e mecânicos está associado à maior área superficial específica do CPII Z-LAB constituinte do CAA-LAB, resultando em uma maior reatividade e em um maior empacotamento entre os materiais granulares e, assim, em maiores resistências já nas primeiras idades e em uma matriz mais densa quando no estado endurecido.

Assim, a partir do exposto no presente trabalho, pode-se constatar que o resíduo de cerâmica vermelha, gerado no processo de produção das indústrias constituintes dos arranjos produtivos locais de base mineral do Estado de São Paulo, quando finamente moído, mostrou-se adequado para a produção de concretos autoadensáveis de alta resistência, sendo incorporado na forma de adição mineral, tanto na produção de cimento composto quanto como adição ao concreto, melhorando a estabilidade e as propriedades físicas e mecânicas dos concretos.

Este fato, associado à proximidade geográfica entre as indústrias ceramistas, as indústrias cimenteiras e as centrais fornecedoras de concreto fazem da pozolana obtida a partir do resíduo de cerâmica vermelha uma alternativa em potencial para uso como adição mineral na produção de cimento Portland e concreto aplicados na construção civil. Isso resultaria em vantagens ambientais, econômicas e tecnológicas, permitindo a reciclagem de um resíduo que, caso contrário, seria depositado em aterros.

\section{BIBLIOGRAFIA}

[1] BATTAGIN, A. F. "Cimento Portland”, In: ISAIA, G. C. (ed),Concreto: ciência e tecnologia, São Paulo, IBRACON, 2011, pp.185-232.

[2] AÏTCIN, P.-C. Concreto de alto desempenho, São Paulo, PINI, 2000.

[3] NEHDI, M., MINDESS, S., AÏTCIN, P.-C. "Rheology of high-performance concrete: effect of ultrafine particles",Cement and Concrete Research, v.28, n.5, pp.687-697, 1998.

[4] MEHTA, P. K., MONTEIRO, P. J. M. Concreto: microestrutura, propriedades e materiais, 2 ed., São Paulo, IBRACON, 2014.

[5] DAL MOLIN, D. C. C. "Adições minerais". In: ISAIA, G. C. (ed). Concreto: ciência e tecnologia, São Paulo, IBRACON, 2011, pp.261-309.

[6] MAS, M. A., REIG, L., MONZO, J., et al."Ceramic tiles waste as replacement material in Portland cement”, 2015. Disponível: http://www.icevirtuallibrary.com/content/article/10.1680/adcr.15.00021 Acessado em 23/06/2015.

[7] AY, N., ÜNAL, M. "The use of waste ceramic tile in cement production",Cement and Concrete Research, v.30, n.3, pp.497-499, 2000.

[8] TOLEDO FILHO, R. D., GONÇALVES, J.P., AMERICANO, B.B., et al."Potential for use of crushed waste calcined-clay brick as a supplementary cementitious material in Brazil", Cement and Concrete Research, v.37, n.9, pp.1357-1365, 2007.

[9] REIG, L., TASHIMA, M.M., BORRACHERO, M.V., et al. "Properties and microstructure of alkaliactivated red clay brick waste", Construction and Building Materials, v.43, pp.98-106, 2013.

[10] SILVA, J., BRITO, J., VEIGA, R. "Incorporation of fine ceramics in mortars",Construction and Building Materials, v.23, n.1, pp.556-564, 2009.

[11] PACHECO-TORGAL, F., JALALI, S. "Reusing ceramic wastes in concrete",Construction and Building Materials, v.24, n.5, pp.832-838, 2010.

[12] PEREIRA-DE-OLIVEIRA, L. A., CASTRO-GOMES, J. P., SANTOS, P. M. S. "The potential pozzolanic activity of glass and red-clay ceramic waste as cement mortars components",Construction and Building Materials, v.1, pp.197-203, 2012.

[13] GOMES, P. C. C., BARROS, A. R.. Métodos de dosagem de concreto autoadensável, São Paulo, PINI, 2009.

[14] REPETTE, W. L. "Concreto autoadensável: características e aplicação",Revista Téchne, v.135, pp.56-60, 2008.

[15] EFNARC. Specification and guidelines for self-compacting concrete, 2002.

[16] TUTIKIAN, B. F., DAL MOLIN, D. C. Concreto autoadensável, São Paulo, PINI, 2008.

[17] CASTRO, A. L., GARCIA, E., SANTOS, R.F.C., et al."Avaliação da reatividade de pozolana obtida a partir de resíduos de cerâmica vermelha”, In: Anais do $58^{\circ}$ Congresso Brasileiro de Cerâmica, pp.3034-3045, 
Bento Gonçalves/RS, 2014.

[18] SILVA, M. G. "Cimentos Portland com adições minerais". In: ISAIA, G. C. (ed). Materiais de construção civil e princípios de ciências e engenharia de materiais, São Paulo, IBRACON, 2010, pp.791-823.

[19] ASSOCIAÇÃO BRASILEIRA DE NORMAS TÉCNICAS (ABNT). Materiais pozolânicos: requisitos NBR 12653, Rio de Janeiro, 2014.

[20] CASTRO, A. L., SANTOS, R. F. C., GONCALVES, K. M., et al. "Caracterização de cimentos compostos com resíduo da indústria de cerâmica vermelha", Cerâmica, v.63, n.365, pp.65-76, 2017.

[21] ASSOCIAÇÃO BRASILEIRA DE NORMAS TÉCNICAS (ABNT). Cimento Portland composto: especificação - NBR 11578, Rio de Janeiro, 1991.

[22] GOMES, P. C. C., Optimization and characterization of high-strength self-compacting concrete, Tese de D.Sc., Escola Tècnica Superior D'Enginyers de Camins, Canals i Ports de Barcelona, Universitat Politècnica de Catalunya, Barcelona, Espanha, 2002.

[23] ASSOCIAÇÃO BRASILEIRA DE NORMAS TÉCNICAS (ABNT). Calda de cimento para injeção Parte 2: determinação do índice de fluidez e da vida útil - NBR 7681-2, Rio de Janeiro, 2013.

[24] KANTRO, D. L. "Influence of water-reducing admixtures on properties of cement paste: a miniature slump test",Cement, Concrete, and Aggregates, v.2, n.2, pp.95-108, 1980.

[25] De LARRARD, F., BOSC, F., CATHERINE, C., et al. "The AFREM method for the mix-design of high performance concrete",Materials and Structures, v.30, pp.439-446, 1997.

[26] ASSOCIAÇÃO BRASILEIRA DE NORMAS TÉCNICAS (ABNT). Agregados: determinação da massa unitária e do volume de vazios - NBR NM 45, Rio de Janeiro, 2006.

[27] ASSOCIAÇÃO BRASILEIRA DE NORMAS TÉCNICAS (ABNT). Concreto autoadensável - Parte 2: determinação do espalhamento e do tempo de escoamento, método do cone de Abrams - NBR 15823-2, Rio de Janeiro, 2010.

[28] ASSOCIAÇÃO BRASILEIRA DE NORMAS TÉCNICAS (ABNT). Concreto autoadensável - Parte 3: determinação da habilidade passante, método do anel J- NBR 15823-3, Rio de Janeiro, 2010.

[29] ASSOCIAÇÃO BRASILEIRA DE NORMAS TÉCNICAS (ABNT). Concreto autoadensável - Parte 4: determinação da habilidade passante, método da caixa L - NBR 15823-4, Rio de Janeiro, 2010.

[30] ASSOCIAÇÃO BRASILEIRA DE NORMAS TÉCNICAS (ABNT). Concreto autoadensável - Parte 5: determinação da viscosidade, método do funil V - NBR 15823-5, Rio de Janeiro, 2010.

[31] ASSOCIAÇÃO BRASILEIRA DE NORMAS TÉCNICAS (ABNT). Concreto autoadensável - Parte 6: determinação da resistência à segregação, método da coluna de segregação - NBR 15823-6, Rio de Janeiro, 2010.

[32] ASSOCIAÇÃO BRASILEIRA DE NORMAS TÉCNICAS (ABNT). Concreto autoadensável - Parte 1: classificação, controle e aceitação no estado fresco - NBR 15823-1, Rio de Janeiro, 2010.

[33] ASSOCIAÇÃO BRASILEIRA DE NORMAS TÉCNICAS (ABNT). Argamassa e concreto endurecidos: determinação da absorção de água, índice de vazios e massa específica - NBR 9778, Rio de Janeiro, 2005.

[34] ASSOCIAÇÃO BRASILEIRA DE NORMAS TÉCNICAS (ABNT). Concreto: ensaio de compressão de corpos de prova cilíndricos - NBR 5739, Rio de Janeiro, 2007.

[35] HELENE, P. R. L. "La agresividad del medio y la durabilidad del hormigón”,Hormigón, AATH, n.10, pp.25-35, 1983. 